\title{
Ecological and hydrochemical water properties of surface watercourses and aspects of inhabitant nosology in Dubna city
}

\author{
I.A. Kirpichev, O.A. Savvateeva* \\ Dubna State University, 141982, Universitetskaya, 19, Dubna, Moscow region
}

\begin{abstract}
The article is devoted to the study of the ecological and hydrochemical parameters of rivers Volga and Dubna within Dubna city, Moscow region, while considering both the actual ecological and hydrochemical indicators, as well as the biochemical and ecotoxicological characteristics of watercourses. It is shown that watercourses are constantly subjected to anthropogenic pressure. It inevitably leads to the arrival of a number of pollutants including heavy metals that can destroy the existing ecological balance of reservoirs. Since the Volga is a source of surface water supply for Dubna city, and both rivers are popular in terms of recreational activities and fishing, an urgent issue is to study the nosologies of the urban population caused by the impact of the waters of both rivers. It is shown that the high probability of the potential development of environmental-related nosologies is not currently fixed, the carcinogenic risk to the health of the population of Dubna city has a minimal, low and moderate degree as a result of surface water pollution, the noncarcinogenic danger from surface water pollution has a minimum, permissible and moderate degree of danger. The critical organs and body systems of the population of the territory are primarily the gastrointestinal tract, central nervous, nervous and cardiovascular systems. Attention should be paid to monitoring in surface water bodies such contaminants as magnesium, nitrite, nitrate, and ammonium salts, phosphates, zinc, copper, and lead.
\end{abstract}

\section{Introduction}

The evolvement of modern cities is progressing rapidly. Every year, new enterprises and industrial complexes appear, and the network of highways grows. At the same time, there is an increase in the amount of pollutants released into all natural environments.

Historically, cities arose along the banks of large rivers and reservoirs. The Volga River is no exception. As a major waterway, it has been serving as a source of resources for the residents of the cities that have appeared on its catchment area.

\footnotetext{
* Corresponding author: ol savvateeva@mail.ru
} 
Dubna in the Moscow Region is a science city founded in 1956. The history of the city has roots dating back to the 11 th century. However, Dubna city gained wide fame in the 20th century, when the Joint Institute for Nuclear Research was formed here, but even earlier in 1937, the Ivankovskaya hydroelectric dam was built and the Ivankovsky reservoir was formed - a source of water for Moscow.

As on 2020, according to the Federal State Statistics Service the city's population is 74985 people, and a number of enterprises are located on its territory: the Joint Institute for Nuclear Research (JINR), Dubnenskiy mashinostroitelniy zavod named after Fedorov (the company limited by shares), Gosudarstvennoye mashinostroitelnoye konstruktorskoye byuro Raduga named after Bereznyak (the public limited company), Priborny zavod Tensor (the public limited company), Research Institute Atoll (the company limited by shares), Research Institute Prikladnoy akustiki (the federal state unitary enterprise), Mebelnaya fabrika Ecomebel (the limited liability company). Special economic zone of technology development type has been evolving for 15 years, where the number of residents has been growing every year, technologies have become more complicated and a number of employees have been increasing.

The presence of industrial sites and residential areas inevitably leads to the entry of pollutants into water bodies. The objects of research in this work are the Volga River near Dubna, as well as the Dubna River, which flows through the territory of the Moscow region and flows into the Volga above the studied city (Fig. 1). In addition, on the territory of the left bank of the city there are two drainage ditches (North and South), diverting drainage water coming from the Ivankovsky reservoir, as well as wastewater from some enterprises coming into the Volga River.

Contaminants entering into natural water bodies can be divided into several types. Chemical pollution is a change in the natural chemical properties of water due to an increase in the content of harmful impurities in it, both inorganic (mineral salts, acids, alkalis, clay particles) and organic (oil and petroleum products, organic residues, surfactants, pesticides). The main inorganic (mineral) pollutants of fresh water are a variety of chemical compounds that are toxic to the inhabitants of the aquatic environment. These are compounds of arsenic, lead, cadmium, mercury, chromium, copper, and fluorine. Most of them fall into the water as a result of human activity. Heavy metals are absorbed by phytoplankton, and then transferred along the food chain to more highly organized organisms. It is necessary to mention the enterprises of the food industry and agriculture among the main sources of pollution of the hydrosphere with mineral substances and biogenic elements. [1]

On the one hand, water is the basis of life and, on the other hand the main risk factor for the development of infectious and chemical diseases. Infectious diseases are the most common and widespread health risk factor associated with drinking water, and the control of microbiological indicators of water quality is the primary task of any populated area. [2, 3] Among the chemical polluting components, only some lead to acute health disorders and under certain conditions: these are situations of extreme pollution during accidents, cumulative effects during prolonged exposure (currently heavy metals and drugs are mostly being studied) $[4,5]$, or substances that are not typical for the natural conditions of the aquatic environment, synthesized artificially $[6,7]$. 


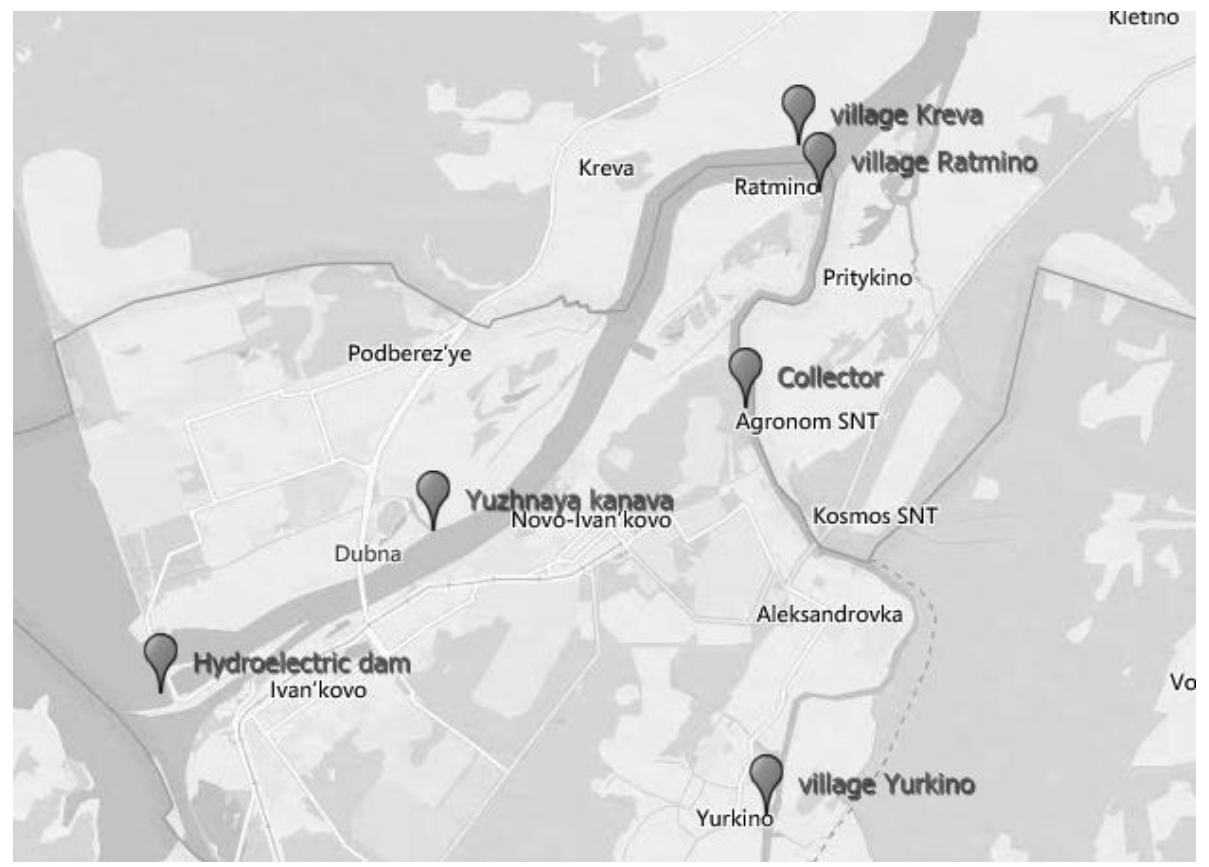

Figure 1. Map of water sampling stations from the Volga and Dubna (1 - Hydroelectric dam; 2 Yuzhnaya kanava; 3 - village Kreva; 4 - village Yurkino; 5 - Collector; 6 - village Ratmino)

Moreover, it should be noted that the study of nosologies is mainly carried out for large cities [8] and large industrial facilities [9], while a very significant part of the world's population lives in small settlements.

Considered in this paper, both the Volga and Dubna are objects of multidirectional use for residents of Dubna city: the Volga is a surface source of water supply, both rivers are used as objects of recreation and fishing, transport arteries. And if the possibility of adverse infectious effects, especially from the Volga, is leveled by water treatment and monitoring systems, then the chemical effects should be monitored and investigated.

The purpose of the study is conducting the initial stage of the study of the ecological and hydrochemical water properties of surface watercourses within Dubna city (the Volga and Dubna rivers), as well as analyzing the relationship with the health status of residents.

\section{Materials and methods of the study}

The study was conducted on the basis of the educational and scientific laboratory for the analysis of environmental objects of Dubna State University in 2019-2021. Figure 1 shows the location of water sampling points from watercourses.

Samples were taken in a plastic container with a volume of 21 from the shore using a 3meter-long sampler, according to Russian state standards 17.1.5.05-85. and 31861-2012.

Several methods were used to determine the hydrochemical parameters of water: potentiometric, conductometric, titrimetric, photometric, and atomic absorption. The $\mathrm{pH}$ value of the sample was determined by the potentiometric method using the $\mathrm{pH}$ meter $\mathrm{pH}$ 150MI, the specific electrical conductivity using the conductometric method (conductometer MARK-603). The total hardness, the content of calcium, magnesium and chlorides in the water were determined by the titrimetric method. The concentration of the ammonium ion, nitrite ion, nitrate ion, phosphate ion, and total iron was determined on a KFK-30M3 spectrophotometer according to GOST methods. 
The concentrations of heavy metals were determined on the QUANTUM-2A atomic absorption spectrometer by evaporation of the aliquot of a $500 \mathrm{ml}$ water sample to $50 \mathrm{ml}$ and further bringing the $\mathrm{pH}$ of the medium to a value of $1-2$ by adding nitric acid (NHO3) in a ratio of $5 \mathrm{ml}$ per 11 of the sample. [10]

Calculations and assessment of environmental health risks from chemical exposure of surface waters is made on the basis of the "Guidelines for the assessment of risk to public health when exposed to chemical pollutants of the environment» [11], Guidelines of «Complex hygienic assessment of the tension degree of the health and environmental situation in various areas due to contamination by toxicants habitat of the population» [12], Methodological recommendations on «Assessment of risk to human health from chemical and physical factors of the environment» [13], as well as the results of research and practical work of specialists of the Center for Environmental Policy of Russia [14], the Research Institute of Human Ecology and Environmental Hygiene named after Sysin [15] risk assessment methods based on domestic principles of hygienic regulation of harmful environmental factors, private models and results of epidemiological studies) and some other methods [16-19].

\section{Results of the study and their discussion}

\subsection{Ecological and hydrochemical water properties of surface watercourses of Dubna city}

Data on the main ecological and hydrochemical water properties of the rivers Volga and Dubna within Dubna city shown in table 1.

Table 1. Concentrations of main ecological and hydrochemical parameters of water in the Volga and Dubna on the territory of Dubna city

\begin{tabular}{|c|c|c|c|c|c|c|c|}
\hline \multirow[b]{3}{*}{ Indicator } & \multicolumn{6}{|c|}{ Values at selection points } & \multirow[b]{3}{*}{ LOC } \\
\hline & \multicolumn{3}{|c|}{ the Volga } & \multicolumn{3}{|c|}{ the Dubna } & \\
\hline & $\begin{array}{l}\text { Hydroel } \\
\text { ectric } \\
\text { dam }\end{array}$ & $\begin{array}{c}\text { Yuzhn } \\
\text { aya } \\
\text { kanava }\end{array}$ & $\begin{array}{l}\text { Village } \\
\text { Kreva }\end{array}$ & $\begin{array}{l}\text { Village } \\
\text { Yurkino }\end{array}$ & Collector & Ratmino & \\
\hline $\mathrm{pH}$ & 8.21 & 8.02 & 8.10 & 8.25 & 8.20 & 8.09 & $\begin{array}{c}6.5- \\
8.5\end{array}$ \\
\hline Hardness, mg-eq/1 & 3.15 & 3.06 & 3.03 & 5.48 & 5.16 & 3.34 & 10 \\
\hline Calcium, mg / 1 & 42.15 & 43.60 & 41.8 & 67.73 & 67.73 & 47.23 & 180 \\
\hline Magnesium, mg/l & 64.98 & 40.34 & 41.6 & 92.10 & 84.33 & 44.53 & 40 \\
\hline $\begin{array}{c}\text { Ammonium ion, } \\
\mathrm{mg} / \mathrm{l}\end{array}$ & 0.40 & 0.32 & 0.35 & 0.52 & 0.43 & 0.44 & 0.5 \\
\hline Nitrite ion, $\mathrm{mg} / 1$ & 0.08 & 0.06 & 0.07 & 0.58 & 0.37 & 0.07 & 3 \\
\hline Nitrate ion, $\mathrm{mg} / \mathrm{l}$ & 1.47 & 1.87 & 2.71 & 2.11 & 2.65 & 2.73 & 40 \\
\hline $\begin{array}{l}\text { Phosphate ion, } \\
\text { mg / 1 }\end{array}$ & 0.14 & 0.11 & 0.17 & 0.77 & 0.58 & 0.25 & 0.2 \\
\hline Chlorides, mg / 1 & 7.9 & 10.28 & 9.93 & 10.16 & 9.86 & 10.6 & 300 \\
\hline Total iron, mg/l & 0.19 & 0.16 & 0.22 & 0.11 & 0.03 & 0.22 & 0.3 \\
\hline
\end{tabular}


During the study, it was found that the water of the Volga and Dubna have similar acidity values, close to a slightly alkaline environment. The hardness level varies from 3.03 $\mathrm{mg}$-eq/l to $5.48 \mathrm{mg}$-eq/l that is the average value, according to the standards. It is noted that the waters of the Volga have less rigidity than the Dubna. Often, the hardness of the water increases at the points that are near busy highways. The values of calcium and magnesium correlate with the values of water hardness, while the concentration of magnesium is quite high in both rivers and often exceeds the maximum permissible.

The ammonium ion is a satellite of relatively recent pollution of the reservoir with biogenic substances. Biogens are the main pollution components that are exported from the catchment area by the surface and groundwater runoff as a result of the agricultural and forestry activities. However, nitrogen and phosphorus are also exported into rivers under natural conditions as a result of the vital activity of biota and erosion processes. This process is combined with the anthropogenic discharge; it contributes to the pollution of natural waters and should be considered a component of such pollution [20]. The concentrations of ammonium nitrogen in the studied reservoirs vary from 0.32 to $0.52 \mathrm{mg} /$ 1 that is close to or even higher than the LOC. There are several sources that can influence this indicator. The waters of the Ivankovsky reservoir, located upstream, often receive untreated runoff from agricultural complexes. The main load from this source falls on the point near the Hydroelectric dam. In the recent 20 years, the concentrations of N-NH4 were slightly decreasing all over of this territory. However, in the zone of large cattle farms, subsoil water locally shows the concentration of N-NH4 equal to 2,5 and 1,0 mg/dm3. [21]. As we move towards the closing gate on the Volga, the values of the ammonium ion change within insignificant limits. A different situation is developing in the waters of the Dubna, where in the summer of 2020 there was a rather serious environmental situation associated with the entry of untreated sewage into the reservoir. As a result of the destruction of the communication system, sewage flowed into the river along with storm water. The situation developed as much as possible upstream of the river, as it approached the village Ratmino values of the ammonium ion begin to decrease.

The concentration of the nitrite ion is quite low and ranges from $0.06-0.58 \mathrm{mg} / 1$. The maximum concentration is observed in the alignment of the village Yurkino, which is due to the transformation of the ammonium ion. However, the nitrate ion concentrations are far below the LOC.

Another component that significantly violates the ecological balance of water bodies is the phosphate ion, the maximum concentration of which is found in the alignment of the same village. The authors attribute this extreme to the possible entry of diffuse water into the reservoir from agricultural land located upstream of the Dubna.

The concentrations of chlorides and total iron do not exceed the LOC in the studied targets. In general, the former are more typical for the winter period of the year and especially manifest themselves during snowmelt; common iron often has a natural origin and is associated with the feeding of watercourses with extremely colored swamp waters.

Table 2. Levels of indicators of the biochemical state of the water of the Volga and Dubna

\begin{tabular}{|c|c|c|c|c|c|c|c|}
\hline \multirow{2}{*}{ Indicator } & \multicolumn{5}{|c|}{ Values at selection points } & \multicolumn{3}{c|}{ the Dubna } \\
\cline { 2 - 8 } & \multicolumn{2}{|c|}{$\begin{array}{c}\text { the Volga } \\
\text { Hydroele } \\
\text { ctric } \\
\text { dam }\end{array}$} & $\begin{array}{c}\text { Yuzhna } \\
\text { ya } \\
\text { kanava }\end{array}$ & $\begin{array}{c}\text { Village } \\
\text { Kreva }\end{array}$ & $\begin{array}{c}\text { Village } \\
\text { Yurkino }\end{array}$ & Collector & Ratmino \\
\hline $\begin{array}{c}\text { Solution O2, } \\
\text { mg/1 }\end{array}$ & 4.28 & 5.76 & 6.13 & 2.14 & 3.10 & 5.54 & $>4$ \\
\hline BOD5 mg/1 & 1.70 & 2.21 & 2.07 & 1.57 & 1.25 & 1.76 & 2 \\
\hline
\end{tabular}


Thus, the dissolved oxygen content is acceptable (4.28-6.13 mg / 1) in the Volga. The opposite situation is typical for the Dubna. In the gates of the village Yurkino and the Collector, the values of oxygen dissolved in water are almost 2 times lower than normal. The values of BOD5 also close to the LOC. The above indicates that the water bodies have an unfavorable situation in terms of contamination with organic substances. A similar pattern is often observed in large cities, it is associated with the anthropogenic load as a result of the discharge of standard-treated wastewater, including from urban wastewater treatment plants. The data in $\mathrm{t}$ able 3 reflect the ecotoxicological state of the studied reservoirs.

Table 3. Level of indicators of the ecotoxicological state of the Volga and Dubna

\begin{tabular}{|c|c|c|c|c|c|c|c|}
\hline \multirow[b]{3}{*}{ Indicator } & \multicolumn{6}{|c|}{ Values at selection points } & \multirow[b]{3}{*}{ LOC } \\
\hline & \multicolumn{3}{|c|}{ the Volga } & \multicolumn{3}{|c|}{ the Dubna } & \\
\hline & $\begin{array}{l}\text { Hydroele } \\
\text { ctric } \\
\text { dam }\end{array}$ & $\begin{array}{c}\text { Yuzhna } \\
\text { ya } \\
\text { kanava }\end{array}$ & $\begin{array}{l}\text { Village } \\
\text { Kreva }\end{array}$ & $\begin{array}{l}\text { Village } \\
\text { Yurkino }\end{array}$ & Collector & Ratmino & \\
\hline Lead, mg / 1 & 0.00226 & 0.00392 & 0.00227 & 0.00121 & 0.0017 & 0.00491 & 0.1 \\
\hline Zinc, mg / 1 & 0.01605 & 0.01123 & 0.01466 & 0.00077 & 0.0009 & 0.01544 & 0.01 \\
\hline Copper, mg/ 1 & 0.0021 & 0.0028 & 0.0025 & 0.0020 & 0.002 & 0.0024 & 0.001 \\
\hline $\begin{array}{c}\text { Cadmium, } \\
\mathrm{mg} / 1\end{array}$ & 0.00013 & 0.00027 & 0.00009 & 0.00023 & 0.00019 & 0.00014 & 0.001 \\
\hline Nickel, mg / 1 & 0.00095 & 0.00076 & 0.00101 & 0.00111 & 0.00111 & 0.00118 & 0.1 \\
\hline
\end{tabular}

The study revealed that the content of lead, cadmium and nickel in the waters of the Volga and Dubna does not exceed the established standards. However, the presence of zinc and copper is noticeable.

Zinc (0.0009-0.01605 mg / 1) most likely comes from the waters of the Volga from the Ivankovsky reservoir. This is the most important element. No clear patterns in the distribution of the concentration in the water of the Volga could be traced [22]. But its concentrations are higher in the Volga waters near Dubna than in the Dubna river itself. The copper content varies in the range from 0.002 to $0.0028 \mathrm{mg} / 1$ and exceeds the LOC at almost all points. In part, this indicator is related to natural factors. Increased concentrations of copper are found almost throughout the territory of the Ivankovsky and Uglich reservoirs. Basically, these elements accumulate in the bottom sediments of the mouths of watercourses. Here, they can reach LOC values and exceed it by more than three times [23].

\subsection{Characteristics of hazards and risks to the health of the population of Dubna city from priority chemical pollutants of surface water}

Based on the above, when analyzing the potential impact of surface water on the health of the population of Dubna city, special attention should be paid to such contaminants as magnesium, ammonium, phosphates, zinc and copper.

At elevated concentrations of magnesium in surface waters (even if consumed as drinking water) in the human body, its concentrations rarely reach critical levels, since they 
are excreted by the kidneys. At the same time, increased concentrations of the component may indicate increased water hardness, which is confirmed by many archival studies [10] Constant consumption of highly mineralized water contributes to the occurrence of urolithiasis, sclerosis, hypertension, which are indeed often recorded in residents of the entire Moscow region.

In conditions where the $\mathrm{pH}$ of water varies between 8-11, both ammonium and ammonia are found. The sum of ammonia and ammonium is the total ammonium nitrogen. Ammonia is particularly dangerous when interacting with other chemical elements in water. Various environmental factors, such as $\mathrm{pH}$ and temperature, can also increase the toxicity of ammonia. The presence of elevated levels of such a contaminant as ammonium nitrogen indicates the close location of the source of contamination. In the case of Dubna, most likely, this aspect is related to diffuse pollution, which requires detailed consideration. Directly, ammonium nitrogen does not generate a noticeable effect on the health of the population.

Increased levels of phosphates complicate the processes of water treatment, promote the development of blue-green algae, which is very essential in the conditions of using the waters of the Volga as a source of water supply. In the human body, phosphates can interfere with the absorption of calcium, as well as lead to a weakening of the immune system, since they reduce the membrane potential of cells.

The biological role of zinc is twofold and not fully understood. With an excess of zinc, the development of anemia, kidney damage is observed. Zinc tends to accumulate in the liver, prostate, and retina. [3, 24]

It is believed that the increased content of copper in water causes damage to the liver and kidneys, leading to a weakening of the immune system. In addition, copper is characterized by an irritant effect on the gastrointestinal tract, is a cytotoxic agent. [3, 24]

Human contact with the components of the hydrosphere occurs through the upper respiratory tract (inhalation exposure), the gastrointestinal tract (oral exposure) and through the skin (cutaneous exposure). The first pathway is the least studied, but its contribution to the deterioration of health, with the exception of emergencies, is the smallest. With oral exposure, the gastrointestinal tract is primarily affected, but most often the cumulative effect leads to the spread of exposure to other organs and tissues. Skin contact with water to the greatest extent leads to the emergence of infectious nosologies of non-chemical nature. $[11,13,16,24]$

Thus, in the perspective of the objects considered by the authors of the article, the greatest attention should be paid to oral exposure. Estimates according to key Russian approaches [10-18] show that the carcinogenic risk to the health of the population of Dubna city as a result of surface water pollution has a low, minimal and medium degree. Noncarcinogenic hazard from surface water pollution has a minimum, moderate and acceptable degree of danger. Substances - pollutants of surface water, forming an increased environmental risk to the health of the population of Dubna city in addition to those discussed above, are lead, nitrites, and nitrates. [25]

\section{Conclusions}

The state of the surface waters of the territory of Dubna city is quite good, but in the waters of the Volga and the Dubna rivers there are parameters whose concentrations exceed the established standards. These indicators include BOD5, magnesium, copper, zinc, nitrite ion, ammonium ion, and phosphate ion. In the waters of the Dubna, the concentrations of some of these components are higher than in the waters of the Volga. At the same time, there is a clear pattern of increasing the concentration of these substances as they move up the mouth of the Dubna. At the outlet of the river, the available concentrations of contaminants are 
diluted; upstream of the river. Dubna city is home to a large number of businesses that bring a large amount of chemicals into the river waters.

Based on the analysis of environmental risks to public health of Dubna city, Moscow region against chemical pollution of surface water and the potential development of ecorelated diseases, we can conclude that a high probability for both indicators is currently not available. The critical organs and body systems of the population of the territory should primarily be considered the gastrointestinal tract, central nervous, nervous and cardiovascular systems. However, attention should be paid to monitoring surface water contaminants such as magnesium, nitrite nitrogen, nitrate and ammonium salts, phosphates, zinc, copper and lead.

\section{References}

1. O.E. Saenko, T.P. Trushina, Environmental fundamentals of environmental management (KNORUS, Moscow, 2017) [in Russian]

2. A.A. Korolev, M.V. Bogdanov, Al.A. Korolev, E.I. Nikitenko, A.V. Kulikov, Medical ecology )( Academy, Moscow, 2008) [in Russian]

3. V.P. Ivanov, N.V. Ivanova, A.V. Polonikov, Medical ecology. (SpetsLit, St. Petersburg, 2012) [in Russian]

4. J.-L. Liu, M.-H. Wong. Environment International, 59, 208-224 (2013)

5. V. Geissen, H. Mol, E. Klumpp, G. Umlauf, M. Nadal, M. van der Ploeg, S.E.A.T.M. van de Zee, C.J. Ritsema, Int. Soil and Water Conservation Res., 3(1), 57-65 (2015)

6. X. Qu, J. Brame, Q.r Li, P.J.J. Alvarez, Accounts of Chem. Res., 46(3), 834-843 (2013)

7. A.A. Koelmans, N.H. Mohamed Nor, E. Hermsen, M. Kooi, S.M. Mintenig, J. De France. Water Research, 155, 410-422 (2019)

8. W. Brack, V. Dulio, M. Ågerstrand et al.. Sc. of the Total Env., 576, 720-737 (2017)

9. A. Vengosh, R.B. Jackson, N. Warner, T.H. Darrah, A. Kondash, Env. Sc. and Techn. 48(15), 8334-8348 (2014)

10. I.V. Rogovaya, R.G. Dzhamalov, S.V. Morzhukhina, M.P. Osmachko, Env. Geosc., 1, 39-48 (2008) [in Russian]

11. Guidelines for public health risk exposed to chem. substances, contaminants assessing. First Deputy Min. health care. Russian Federation, Head. State. San. Doctor of the Russian Federation March 5, 2004143 p. [in Russian]

12. A comprehensive hygienic assessment of the degree of tension in the medical and environmental situation of various territories due to the contamination of the population's habitat with toxicants. Guidelines. San. Doctor of Russia № 2510/5716-97-32 30.07.97. [in Russian]

13. Assessment of public health risk from chemical and physical factors of human habitat. Guidelines. San. doctor in the Novosibirsk region. (2003). [in Russian]

14. Guidelines for processing and analysis of data for decision-making in the field of environmental protection and public health. Ministry of Health of the Russian Federation 27.02.2001 № 11-3/61-09. [in Russian]

15. Resolution «On Using the Risk Assessment Methodology for Environmental Quality and Public Health Management in the Russian Federation». State. San. doctor of the 
Russian Federation № 25, State Inspector of the Russian Federation for Nature Protection № 03-19/24-3483 10.11.97. [in Russian]

16. S.L. Avaliani, B.A. Revich, V.M. Zakharov, Monitoring of human and environmental health (Center for Environmental Policy of Russia, Moscow, 2001-2004) [in Russian]

17. A.V. ,Kiselev, K.B. Friedman, Health risk assessment. Approaches to use in medical and environmental research and environmental quality management practices (St. Petersburg, 1997) [in Russian]

18. B.I. Sinzynys, E.N. Tiantova, O.P. Melekhova, Environmental risk. (Logos, Moscow, 2005) [in Russian]

19. Criteria for public health risks of priority chemicals polluting the environment assessing. Guidelines. (Moscow, 2001) [in Russian]

20. N.I. Koronkevich, S.V. Dolgov, E.A. Kashutina, et al., Water Resour. 46, 137-144 (2019).

21. N.V. Kirpichnikova, E.E. Lapina, V.V. Kudryashova, Water Resour 47, 721-730 (2020)

22. T.I. Moiseenko, N.A. Gashkina, Y.N. Sharova, L.P. Kudryavtseva, Ecotoxicol. Environ. Saf. 71 (3), 837-850 (2008)

23. M.Yu. Lychagin, A.N. Tkachenko, N.S. Kasimov, S.B. Kroonenberg, J. Coastal Res. 31(4), 859-868 (2015)

24. A.N. Stozharov, Medical ecology (Vysh. shk., Minsk, 2007) [in Russian]

25. I.A. Kirpichev, O.A. Savvateeva, R.G. Dzhamalov, E.A. Starostin, Advances in current natural sciences, 12, 85-91 (2020) [in Russian] 